\title{
Placenta Percreta in First Trimester Pregnancy: A Case Report and Review of Literature
}

\author{
Chowdhury $F^{1}$, Ferdousi $S^{2}$, Beg $A^{3}$, Islam $M^{4}$
}

\begin{abstract}
Placenta percreta is a rare condition and extremely rare in first trimester of pregnancy. It is a life threatening obstetric condition specially in undiagnosed cases. Here we report a case of 32 years $5^{\text {th }}$ gravid woman having history of previous one cesarian section(C/S) and two dilatation and curettage(D\&C), who presented to us with life threatening vaginal bleeding during the attempt of curettage of 12 weeks missed pregnancy. Along with resuscitation emergency hysterectomy was done. Placenta was found in lower segment of uterus invading up to serous coat. Histopathology also confirmed placenta percreta. She received 6 units of blood. She was discharged from hospital after 7 days in good health.
\end{abstract}

CBMJ 2016 January: Vol. 05 No. 01 P: 46-49

Key words: Placenta percreta.

\section{Introduction}

Placenta percreta is a rare condition and extremely rare in first trimester of pregnancy. It is the severe form of abnormal placentation. Three types of abnormal invasiveness of placenta is found, according to severity of invasion of chorionic villi through the decidua and myometrium. These are placenta accreta, increta and percreta. In placenta accreta, the placenta penetrates beyond the endometrial lining and attaches too strongly to muscular layer of uterine wall, but does not invade it. In placenta increta, the placenta invades into the myometrium. In placenta percreta, the placenta invades through full thickness of the myometrium, and can attach to adjacent organs of abdomen, usually bladder. The diagnosis of placental adhesion is known to be difficult during the first trimester, with a lower rate of detection and lower accuracy compared with those obtained in the third trimester ${ }^{1}$. It is usually discovered during dilatation and curettage when massive bleeding occurs due to invasion of the myometrium by placenta ${ }^{2-9}$. The currently known prenatal sonographic characteristics of placenta accreta in first trimester of pregnancy are a low lying gestational sac and diffuse dilatation of intraplacental vessels(lacunae) traversing the lower uterine corpus ${ }^{1}$. Although exact pathogenesis is unknown, absence or defective formation of decidua is related with placenta accreta. This abnormal invasion may be focal, or whole of the placenta may invade the uterine wall specially in placenta praevia cases $^{10,11,12}$. Decidual maldevelopment in placenta accreta is usually associated with previous instrumentation as in the cases of prior cesarean section or uterine curratages ${ }^{13}$. Women at greatest risk of placenta accreta are those who have myometrial damage caused by a previous cesarean delivery with anterior or posterior placenta praevia overlying the previous uterine scar ${ }^{14}$.

1. *Ferdousi Chowdhury,

Associate Professor and Head of Department Obstetrics \& gynecology, Addin Women Medical college Hospital, Dhaka.

2. Shamima Ferdousi,

Associate Professor and Head of Department of Pathology. Ibrahim Medical College. Dhaka.

3. Dr. Ayesha Beg Junior Consultant Upazilla Health Complex, Gouripur Ministry of Health, Govt. of Bangladesh

4. Dr. Md. Aminul Islam

Associate Professor of Medicine.

Community Based Medical College, Bangladesh.

- Address of Correspondence:

Email : ferdousi_sbmc@yahoo.com

Mobile: 01758870537 


\section{Case Report}

A 32 years old, $5^{\text {th }}$ gravid woman was admitted $1^{\text {st }}$ June 2013, with severe per vaginal bleeding having history of attempt of D\&C for 12 weeks missed abortion. Patient had past obstetric history of one child of 10 years old delivered by cesarean section, three miscarriages and two times D\&C for termination of missed pregnancies. Her present pregnancy was diagnosed missed at 11 weeks. Then oral and vaginal Prostaglandins were given for termination, but there was no response for one week. Then D\&C was attempted at local clinic. But at the begining of D\&C severe bleeding started.Immidiate rescucitation with blood was started and patient was shifted to our hospital by packing the vagina.

On admission her blood pressure was within normal range but tachycardia was present.On abdominal examination uterus was not palpable and abdomen was not distended. Vaginal pack was soaked and after removal of the pack severe vaginal bleeding was seen. Clinicaly placenta accreta was suspected and laparotomy was done. After opening the abdomen, body of the uterus was found normal in size but lower portion was distended and placenta was found encroaching and invading the lower segment upto serous coat. Immidiately hysterectomy was done. During separation of urinary bladder from lower segment communicating vessels are found between placenta and urinary bladder. Bladder was injured and it was repaired after hysterectomy. Six units of blood was transfused to her. Her postoperative period was uneventful. Urinary bladder catheter was kept for 2 weeks. Patient was discharged after one week with catheter in situ. After one week she came for follow up, then catheter was removed and she voided urine without difficulty. Histological examination of the specimen revealed placenta percreta.

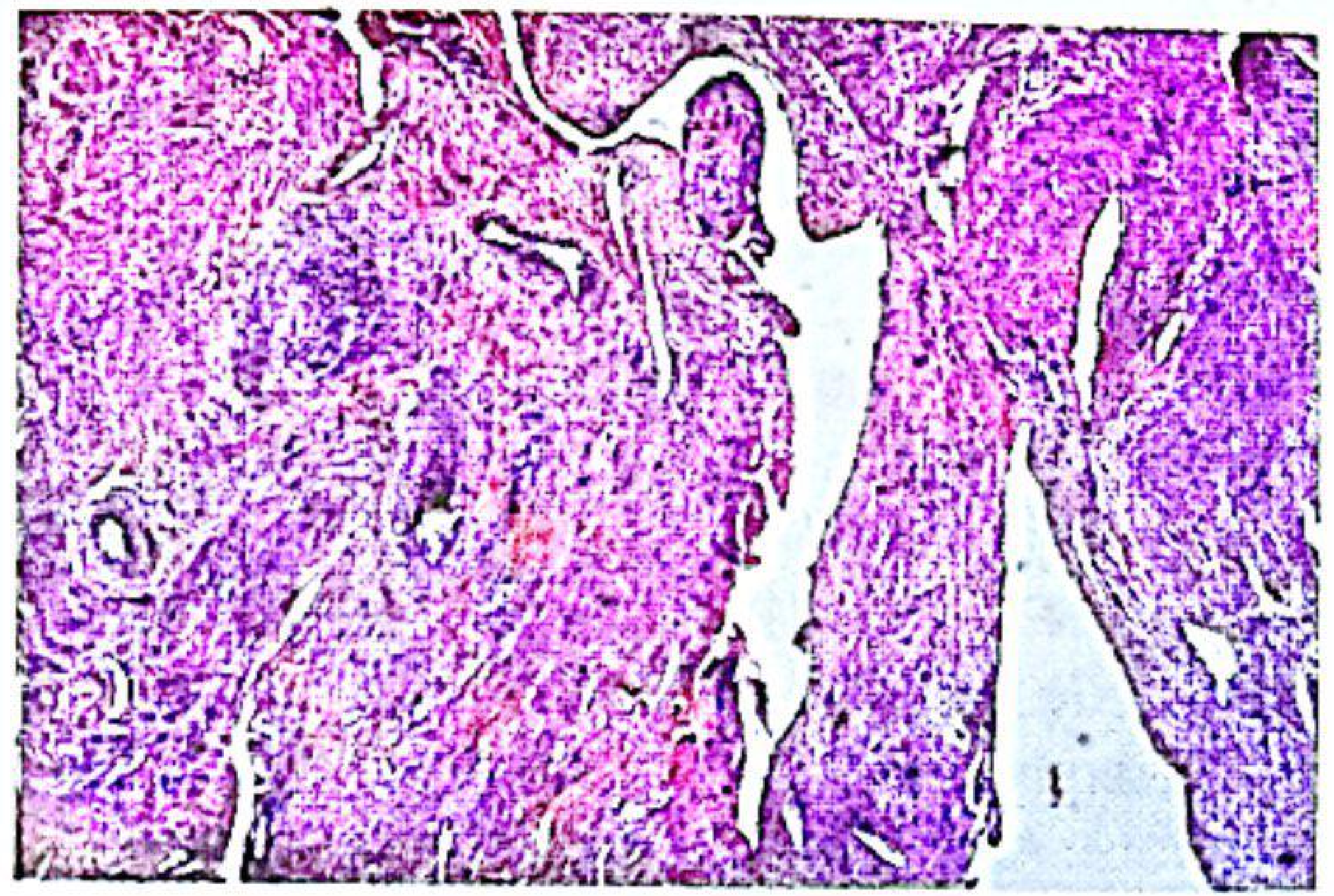

Figure-1: Histopathology showing chorionic vessels within myometrium.

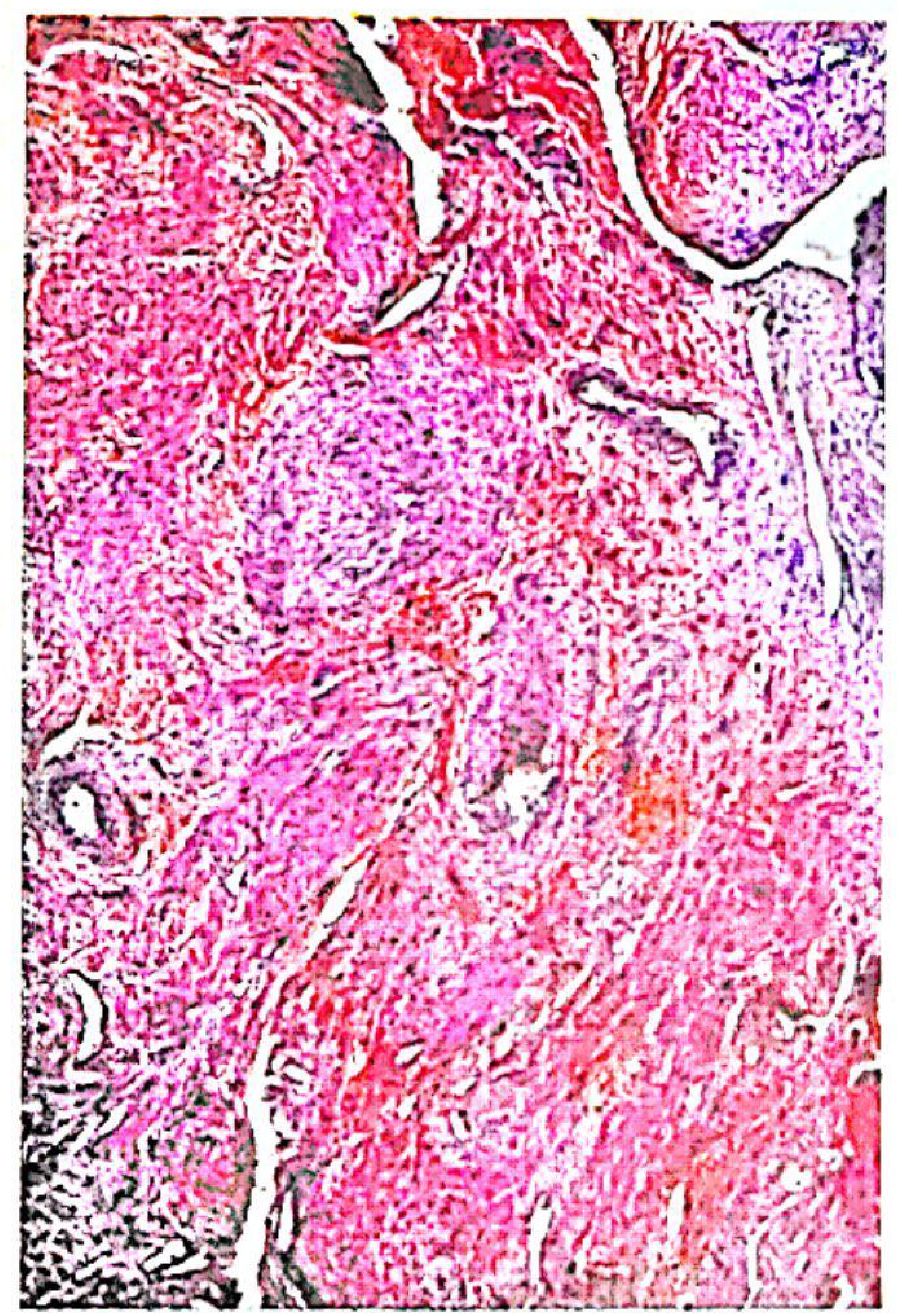

Figure-2: Histopathology showing chorionic vessels within myometrium

\section{Discussions}

Placenta percreta is a rare condition during first and second trimester of pregnancy, so few cases are reported. It is the most severe form of invasive placentation. It can be a lethal problem when encountered during dilatation and evacuation or currettage performed for the termination of first or second trimester pregnancy loss, leading to extensive 
hemorrhage within minutes of initiating the procedure ${ }^{15}$. In such an emergency situation we received our patient.

Profuse vaginal bleeding was the presenting feature after currettage in first trimester missed pregnancy among these cases reported by Hopker $\mathrm{M}^{9}$. et al ,Balkalni $K \mathrm{P}^{16}$ et al and Papadakis $\mathrm{JC}^{17}$. All these cases ultimately needed emergency hysterectomy and thereafter dignosed as cases of placenta percreta. All these cases were also associated with risk factors for invasive placenta like previous cesarean section or D\&C.

Dong $\mathrm{G} \mathrm{J} \mathrm{J}^{18}$ reported a case placenta percreta induced ruptured uterus in 14 weeks pregnancy diagnosed by laparoscopy. That patient was managed by total abdominal hysterectomy. She had previous history of two times dilatation and curratage, which is a risk factor for abnormal invasion of placenta.

$N^{N a n a^{19}}$ et al described a case of second trimester placenta percreta, where after delivery of a 21 weeks macerated fetus, manual removal of the retained placenta was attempted. Then after suspected perforation of uterus, emergency laparotomy was done and diagnosis of plaenta percreta was made. This case was also associated with previous cesarean section.

Another case report by S. Siwatch ${ }^{20}$ noted that a third gravid woman presented to emergency department at her 17 weeks pregnancy with signs of internal hemorrhage. After diagnosis of ruptured uterus, emergency laparotomy was done and part of the placenta was found adherent with uterus. On histology placenta percreta was diagnosed of the excised portion of uteroplacenta. This patient had previous history of two spontaneous abortion, one of which needed evacuation of uterus.

Another case by reported N Gupta ${ }^{15}$ et al was 17 weeks placenta percreta. This patient also had previous history of two cesarean deliveries, came with incomplete abortion and underwent dilatation and currettage. At the end of procedure extensive hemorrhage started and emergency hysterectomy was done.
A Jain ${ }^{21}$ et al reported a histopathological findings of a specimen of uterus. They described that placenta invaded full thickness of uterus upto serosa without any intervening decidua. The uterus was 14 weeks pregnancy with ruptured uterus in a woman having two previous cesarean section. All the reported cases above in first and second trimester pregnancy complicated by placenta accreta

\section{Conclusion}

Women having history of previous cesarean section, dilatation and currettage or manual removal of placenta are at higher risk of invasive placenta specially when pregnancy sac or placenta is low lying. They should be considered for detailed sonographic examination during first trimester of pregnancy. Early diagnosis could result in better obstetric outcome and avoidance of complications.

\section{References}

1. Yang, J. I.,Kim, H. Y., Kim, H. S., Ryu, H. S.(2009), Diagnosis in the first trimester of placenta accreeta with previous cesarean section. Ultrasound ObstetGynecol, 34: 116- 118.Doi:10.1002/uog.6407

2. Harden MA,Walters MD, Valente PT. Postabortal hemorrhagedue to placenta increta: a case report. ObstetGynecol1990; 75: 523-526.

3. Jelsema RD, Zuidema L. First-trimester diagnosed cervicoisthmic pregnancy resulting in term delivery. ObstetGynecol 1992; 80: 517-519.

4. Woolcott RJ, Nicholl M, Gibson JS. A case of placenta percreta presenting in the first trimester of pregnancy. Aust N Z J Obstet Gynaecol1987; 27: 258-260.

5. Ecker JL, Sorem KA, Soodak L, Roberts DJ, Safon LE, Osathanondh R. Placenta increta complicating a firsttrimester abortion. A case report.J Reprod Med 1992; 37: 893-895.

6. Walter AJ, McCullough AE, Patel MD, Cornella JL. Placenta increta presenting as delayed postabortal hemorrhage. Obstet Gynecol1999; 93: 846.

7. Gherman RB, McBrayer $S$, Tichenor J, Wing DA. Placenta increta complicating first-trimesterD\&C. ObstetGynecol1999; 93: 845.

8. Chanrachakul B, Hamontri S, Leopairut J, Herabutya Y. Placenta increta complicating the first trimester abortion. Acta ObstetGynecolScand2001; 80: 467-468.

9. Hopker M, Fleckenstein G, Heyl W, Sattler B, Emons G. Placenta percreta in week 10 of pregnancy with consecutive hysterectomy: case report. Hum Reprod2002; 17: 817-820. 
10. G.Garmi, S. Goldman, E. Shalev, R. Salim, "The effects of decidual injury on the invasion potential of trophoblastic cells", Obstetrics and Gynecology, vol 117, no 1, pp 55-59, 2011. View at publisher. View at google scholar. View at scopus.

11. P. Tantbirojn, C. P. Crum, M, M, Parast, "Pathophysiology of placenta accreeta: the role of decidua and extravilloustrophoblast", Placenta, vol. 9, no 7, pp639-645,, 2008. View at publisher. View at google scholar. View at $S$ copus.

12. K. Benirschke, R. Kaufmann and R. N.Baorgen, NY, USA, $5^{\text {th }}$ edition 2006 .

13. J-J Tseng and M-M Chou, "Differential expression of growth-, angiogenesis- and invasion - related factors in the development of placenta accrteta," Tawaneese 106,2006 . Obstetrics and Gynecology, Vol 45, no 2, pp

14. ACOG Committee on Obstetric practice ACOG Committee opinion number 529 July 2012 ,
Placentaaccreta.

15. Natasha Gupta, Anu Gupta, Marlene Green, HyungShik Kang, and Josef Blankstein; Percreta at 17 Weeks with Consecutive Hysterectomy: A Case Report and Review of the Literature: Case Reports in Obstetrics and Gynecology; Volume 2012 (2012), Article ID 734834.,
16. Balkanli-Kaplan P1, Gucer F, Oz-Puyan F, Yuce MA, Kutlu K; Placenta percreta diagnosed after firsttrimester pregnancy termination: a case report. Reprod Med. 2006 Aug;51(8):662-4.

17. Papadakis JC1, Christodoulou N. Placenta percreta presenting in the first trimester: review of the literature; ClinExpObstet Gynecol. 2008;35(2):98-102.

18. Dong Gyu Jang, Gui Se Ra Lee, JooHee Yoon, Sung Jong Lee, Placenta Percreta-Induced Uterine Rupture Diagnosed By Laparoscopy in tine First Trimester, Int J Med Sci 2011; 8(5):424-427. doi:10.7150/ijms.8

19. Nana PN, Morfaw L, Temkou S, WandjiJC, Leke RIJ, "Placenta percreta occurring in the second trimester: Acase report; Health science dis: Vol 11(1) Mars 2010.

20. S. Siwatch, S Chopra, V Suri, N, Gupta, “ Placentapercreta: rare presentation of hemorrhage in second trimester," BMJ case report, 2013. Doi: $10.1136 / \mathrm{bcr}-2012-007782$.

21. Atul Jain, Gunvanti B. Rathod, PragneshParmar; UTERINE RUPTURE DUE TO PLACENTA PERCRETA IN THE FIRST TRIMESTER OF PREGNANCY; A RARE CASE REPORT, IJMPS. 2012; 3(4): 01-06. 